to be unable to sit up in bed : all the large joints were painful and somewhat swollen, and the ankle joints were also red. The tongue was dry and brown; he had no quickness of breathing, but cough, with expectoration of tenacious mucus sticking to the vessel, and of the rusty pneumonic colour; but there was neither the fine crepitation nor dulness on percussion; and the only stethoscopic symptoms were moist rilles in the back parts of both lungs. Two grains of calomel and one of opium at bedtime, with half-an-ounce of castor oil in the morning, for three days, brought away copious foutid, light-coloured stools, with general relief. The calomel and opium were then diminished one-half, and a draught with two drachms of sulphate of magnesia and half-a-drachm of carbonate of magnesia given in the morning. 'The tongue soon became moist and cleaner, and all the symptoms crradually improved. Ile left the infirmary on the 20th of February, convalescent.

CAsE v. During this period there was another case which might belong to the same class. The patient was a young woman, who had been for some time in delicate health, and her prominent symptoms were severe pains in her limbs and back, which were aggravated at night, and which seemed to be of a rhoumatic character. On Dec. 24th, she became feverish with some cough; and on examining the chest on the 27 th, the greater part of the right lung was found to be dull and impermeable to air, with true crepitating rîles above it. Her convalescence was slow, but her treatment did not require any better means.

REMARks. In neither of these cases was there any affection of the heart; and as the hepatization of the lung was recovered from, it must be considered a fortunate circumstance that the effusion was poured into the substance of the lungs rather than into the pericardium, or upon and within the heart. One advantage the lungs must possess is in the relief which copious expecturation must afford; so different from a shut sac, where absorption alone can remove the eftusion. In one of these cases, where the patient was plethoric and young, the expectoration of mucus, which looked green with bile, was very profuse, and must have greatly assisted in relieving the over-loaded system. The chemistry of expectoration from the lungs, and especially the recent valuable researches of Dr. Beale on the expectoration in pneumonia, in which he has shown that the chlorides which are deficient in the urine during pneumonia, are present in great quantity in the sputa, are in accordance with the rational notion that copious expectorations from nucous membranes are channels by which waste and superfluous matter is got rid of, and it is a branch of investigation very promising of results, and most worthy the attention of chemicial physicians. The treatment in these cases was tried on the principle that the system had been over-loaded, and that nature required assistance in her attempts to relieve herself; and as the liver is one of the chief organs of such climinations, the means were essentially purgative -a moderate dose of calomel and opium at night, and a saline purgative in the morning, so as to insure at least two loose stools. At first, two grains of calomel and one of opium at bedtime, reduced in a few nights to half that quantity, with two drachms of sulphate of magnesia and half a drachm of carhonate of magnesia in the morning, and repeated in the afternoon if necessary, and continued until the symptoms yielded and the tongue became clean, were the chief remedies. When the cough was troublesome, a mixture with ten minims each of antimonial and ipecacuanha wine, with half a drachm cach of syrup of poppies and oxymel of syuills every tive hours, gave relief ; and strict farinaceous diet, without any broths, was enjoined, with tea and lemonade as drink. In all the cases, on admission the tongue was so loaded as clearly to indicate the necessity of aperients. On this simple plan these cases proceeded satisfactorily; neither becume at all unmanageable; nor did it seem necessary to treat the pneumonia otherwise than as a symptom of the rheumatic fever.

Southampton, April 1853.

\section{CASES ILLUSTRATING THE EFFECTS OF} THE WARM BATH IN ASPHYXIA: WITH REMARKS.

By JOSEPH C. S. JENNINGS, Esq.

(Read before the Bath and Bristol Branch, March 24th, 1853.)

CASE I. DROWNING：RESUSCIT ATION AFTER TWENTY MINUTES' IMMERSION : WARX BATH : DEATH.

A. A., aged 80, threw herself into the river Aron, the water reaching to her waist. She was carried by a rapid current three hundred yards down the stream, and round several sharp curves, rolling over in her course; and finally sank in a deep hole. She was then carried under water a distance of forty yards, where her further progress was arrested by a tree growing in the middle of the river, in which her clothes were entangled; her head and body still remaining submersed nearly on the bottorn.

I was present when the body was taken out. The time of complete submersion had been at least twenty minutes. The countenance was livid, and the tongue protruded from the mouth. I immediately applied my mouth to hers, but with some difficulty, from the circumstance of the jaws being toothless, and the muscles thoroughly relaxed. However, holding the nose with one hand, and compressing the thorax with the other, I began to inflate the lungs, and persevered for ten minutes, when I was relieved by the arrival of a strong man, to whom I relinyuished the task of inflation, while I went for a galvanic battery. I previously directed the body to be stripped of wet clothes, enveloped in four blankets, and laid on a board, to avoid damp from the earth. I also directed frictions to be applied. On my return, I found the lips quivering, and feeble attempts at respiration. I immediately applied one wire to the pracordial region, and the other to the head and neck, in the course of the pneumogastric. The heart began to act, and respiration was, in the course of a minute, thoroughly established. The patient speedily began to groan loudly, and continued to do so for four hours, during which time I continued the galvanism. At the end of that period, she was still unable to speak, there being almost complete insensibility; the power of swallowing, had, however, returned, and she took half a glass of brandy. She was then carried home (nearly a mile), groaning loudly all the while; and placed in a warm bed. Hot bottles were applied to the surface of the hody ; but, as it still continued cold, and the patient comatose, I directed a warm bath to be prepared, which was speedily done. After being placed in it for three minutes, she looked about with great anxiety of countenance, and attempted to raise herself. I was just about to speak to her, when I perceived that she convulsively grasped her chest with both hands, and then fell forward in a state of syncope. I immediately lifted her on the bed; but she only gasped a few times. I then applied the wires, but without avail ; and found it impossible to inflate the lungs, although $I$ introduced a flexible tube into the trachea.

I have introduced this case to the notice of the Association, as I am anxious to learn whether galvanism is usually resorted to at receiving houses in such cases, and with what benefit; also whether the warm bath may not frequently, especially at such an advanced age, produce syncope, and so be likely to prove rather injurious than beneficial.

CASE II. ABPHYXIA FROM CARBONIC ACID GAS.

Aaron Hillier, aged 60 , accompanied by Eli Knce, aged 22 , descended into an ice-house, twelve feet in depth. Hillier was going down the ladder first, with a lighted candle ; but had not proceeded many steps before the light was extinguished. He returned, and, having re-lighted the candle, again attempted to descend; but again the light was extinguished. Ignorant of the cause, he procured another light, and a third time went down. This time he reached the bottom, when the lantern was heard to fall. Knee then went down, followed by two others, all three holding each other by the hands. On reaching the bottom of the ladder, Knee became insensible; and it was with difficulty that he could be brought up. A quantity of 
water was then thrown into the house; but Hillier was not brought up for nearly an hour.

On my arrival, about half an hour after Knoe had been extricated, I found him respiring feebly, much convulsed, and totally insensible. After applying the electro-galvanic current, at intervals, for half an hour, he was able to articulate, but remained insensible to what was going on around him for a long time. At length he recovered.

As soon as Hillier was brought up, I inflated the lungs, and applied electro-galvanism for an hour and a half. Frictions and hot blankets were also resorted to. The surface was very cold, in consequence of the large quantity of water which had been thrown upon him while lying on the ice. Respiration and pulsation at the wrist had both ceased ; but, after continuing the current for the time above stated, the jugular vessels became much distended, and the face livid. I then opened the jugular vein, and about half a pint of blood flowed freely. As the body and extremities remained cold, and no attempt at respiration could be perceived, I placed him in a warm bath, but found, within two or three minutes, that galvanism ceased to produce even convulsive action, and that any further attempts to restore animation were useless.

Rexakks. As regards the first case, there can be no reasonable doubt as to the length of time during which the woman was totally immersed. A boy, who saw her walk into the river, ran by the side exhorting her to endeavour to get out, until he saw her finally sink in deep water. He then ran a mile to give the alarm; and an equal portion of time, necessarily occupied by him in so doing, must have been spent by those who came to render assistance. It is to be feared that many lives are sacrificed, under the supposition that the period of immersion has been too long for any efforts to be successful.

I found it requisite to continue the galvanism as above described, as the respiration became feeble and almost imperceptible whenever it was discontinued. While the patient was being carried home-a distance of a mile-and after she was placed in bed, she continued to groan loudly without the assistance of the battery; but the jugulars were much distended, and the lungs and brain probably congested from the long immersion and cold weather.

The ice-house had been opened for some time the day previously to the accident which befel the two men. Might not the carbonic acid have been generated by the oxygen supplied to the carbon of the decomposing and fermenting straw and faggots, upon which the ice was placed ? The same parties had been down on the preceding day, when there was no foul air. If this be correct, such accidents may be prevented for the future.

We constantly find, in medical works, or in charts containing lists of remedies in cases of accident or poisoning, the warm bath recommended as of great value. We must, however, remember that nothing is to be more dreaded than syncope; for then the functions of respiration and circulation are almost or altogether suspended, even although previously thoroughly established. In cases, then, of asphyxia, or (speaking more properly) of apparent death by apnca, frictions and external dry warmth will restore the excitability of the reflex functions ; but, after restoring, we may again exhaust by the continued application of one stimulant, even warmth. But by employing, at intervals, electricity, warmth, and other stimulants, we shall excite the reflex function without exhausting or destroying it.

The cold douche also, if employed immediately after the poor man had been exposed to the carbonic acid, might have saved him by exciting the reflex function; particularly as each bucketful carried with it a current of atmospheric air, which would have been inhaled with each sudden inspiration.

The battery used in the case of drowning was a powerful four-celled Daniell's (kindly lent by W. H. Fox Talbot, Esq., of Lacock Abbey), with a large coil and regulator, and in good working order. The other used was Smee's, by Messrs. Horne and Co., and was such as is commonly emplojed for medical purposes.

Abbey House, Malmesbury, Wiltshire, March 1853.

\section{CASE OF MALIGNANT DISEASE OF OVARIES : SUDDEN DEATH.}

\author{
By GEORGE KING, Esq.
}

CAsE. Miss H., aged 47, a dressmaker, single, of atchectic diathesis, applied to me on 27 th Norember 1852 .

A short time previously, she had discovered a swelling in the left iliac region, which she assured me she had only very recently noticed. On examination, I found a tumour of considerable size occupying the greater part of the iliac region of the left side; it was circumscribed, and gave the sensation of indistinct fluctuation. She had experienced very little pain or inconvenience, nor was the tumour tender.

On examination per vaginam, the os and cervix uteri were found healthy, and the uterus itself appeared of normal size. The catheter entered the bladder obliquely, but no urine was found there. The catamenia had flowed with tolerable regularity until quite recently, and her general health had been tolerably good.

On inquiry, I found that the bowels had been somewhat confined; and thinking there might be some fæcal accumulation, she was moderately purged for several days without diminishing the tumour. At the end of a week, there being some tenderness over the tumour, leeches were applied several times, and calomel with opium given. When the inflammation had subsided, iodide of potassium was administered internally, and the unguentum iodinii comp. applied over the surface of the tumour.

Having persevered in this treatment for some time without any benefit, and feeling that the case was one of considerable obscurity, I urged her to see Mr. Norman, of Bath. He quite agreed with me as to the obscurity of the case, and that the tumour contained fluid; but whether it was an abscess or a softened cancerous tumour, he could not say, although from the history of the case he inclined to the former opinion. In this uncertainty, he recommended that we should wait the further development of the case, and in the interim give some simple tonic. This plan was persevered in for some time, and the case remained in much the same state until the 26th February 1853, when I was hastily summoned to her. I found her in a state of extreme collapse. She revived, however, under the free use of stimulants; and when I saw her next morning, she was almost as well as usual. About eight o'clock that evening, however, I was again hastily summoned to her, as her friends thought she was dying. I went immediately; but before I arrived, she had expired.

Examination of THE Body fifteen hours after death. The body was well formed, but slightly emaciated, and bore the appearance of a person who had died of hæmorrhage. There was a tumour in the left iliac region; but it appeared less prominent than during life. On opening the abdomen, the bladder was found to contain about twelve ounces of urine, and was firmly adherent to a large tumour posteriorly. The tumour, with the bladder and uterus, were removed. The uterus was of normal size. There was a large cyst which originated in the left ovary, occupying the left iliac region, and firmly adherent to the bladder. This tumour contained about a pint of grumous fluid; and behind it, at its base, were several smaller cysts containing encephaloid matter in different degrees of softening. There was no other trace of the left ovary remaining.

The right ovary was not so entirely disorganized; but there were two cysts connected with it, which contained encephaloid matter, but no tluid. There was scarcely a trace of peritoneal inflammation, nor was there any extravasation of fluid in the peritoneal cavity. As far as we could ascertain, there was no disease of any other organ.

The marked absence of pain in this case inclined us to hope that it was not malignant, and faroured the opinion that it was deep seated abscess. The sudden termination of the case was quite unexpected; nor did the post mortem examination clear up the difficulty; and it still remains a question what caused the sudden termination of life.

Melksham, Wiltshire, March 26th, 1853. 